\title{
ENTREVISTA COM MARTA ARRETCHE ${ }^{1}$
}

\author{
Regina Laisner
}

A Profa. Dra. Marta Teresa da Silva Arretche foi entrevistada por mim em seu gabinete no Departamento de Ciência Política (DCP) da Universidade de São Paulo onde é docente atualmente, em meio a muitos livros e papéis. Tudo o que um bom intelectual adora: uma "bagunça organizada" que envolve muito trabalho! No caso dela, trabalho de anos! Fui recebida com um largo sorriso; nada diferente da maneira com que ela sempre se apresenta aos seus estudantes, demais professores e colegas! Era 02 de dezembro de 2014 e Marta, à época, tinha sido recém aprovada em um concurso de professora titular junto ao DCP. Por isso, a entrevista foi feita em clima de comemoração pela importante conquista desta grande intelectual das Ciências Sociais no Brasil.

Além de professora na USP, Marta ocupa várias posições importantes na área, no Brasil e no mundo: também é Diretora do Centro de Estudos da Metrópole (CEM) e editora da Brazilian Political Science Review, assim como membro da Coordenação Adjunta de Programas Especiais da Diretoria Científica da Fundação de Amparo à Pesquisa do Estado de São Paulo (Fapesp). Sua trajetória iniciou-se com estudos em Ciências Sociais na Universidade Federal do Rio Grande do Sul (UFRGS) em Porto Alegre, onde nasceu e cresceu. Mais tarde muda-se para Campinas e cursa mestrado em Ciência Política e doutorado em Ciências

\footnotetext{
${ }^{1}$ Doutora em Ciências Políticas pela Faculdade de Filosofia, Letras e Ciências Humanas (FFLCH) da Universidade de São Paulo (USP) Coordenadora do Núcleo de Estudos em Políticas Públicas (NEPPs) e Professora do Curso de Relações Internacionais da Faculdade de Ciências Humanas e Sociais (FCHS) da Universidade Estadual Paulista Júlio de Mesquita Filho (UNESP).
} 
Sociais na Universidade Estadual de Campinas (Unicamp). Seu pós-doutoramento é feito no Departamento de Ciência Política do Massachussets Institute of Technology (MIT), nos Estados Unidos. Foi também Visiting Fellow do Departament of Political and Social Sciences, no Instituto Universitário Europeu, em Florença, Itália. Atualmente é Bolsista de Produtividade em Pesquisa do Conselho Nacional de Desenvolvimento Científico e Tecnológico(CNPq). Sua área de pesquisa mais recente é Análise institucional e comparada e suas principais áreas de pesquisa incluem a análise comparada dos Estados federativos e a análise comparada dos sistemas de proteção social.

Marta Arretche, como é mais comumente chamada no meio acadêmico, além de ser uma mulher competente, solícita e muito gentil, é atualmente uma referência nos estudos sobre Políticas Públicas no Brasil, entre outros temas. Iniciou seus estudos nesta área durante o mestrado, discorrendo sobre políticas de habitação (na dissertação "Estado e mercado na provisão habitacional: três modelos de Política", orientada pela Profa. Dra. Sônia Miriam Draibe, concluída em 1990). Apresentou suas reflexões a respeito da emergência e desenvolvimento do Welfare State (a exemplo do artigo de 1996, "Emergência e desenvolvimento do welfare state: teorias explicativas", publicado na Revista Brasileira de Informação Bibliográfica em Ciências Sociais), que tornou-se uma referência no debate sobre o tema. Avançou seus estudos apresentando uma discussão sobre o sistema de proteção social no Brasil (cuja referência é o artigo "O sistema de proteção social no Brasil: em direção a um modelo centralizado", publicado em São Paulo em Perspectiva, em 1997) e abordou temas que se tornarão essenciais na sua trajetória: descentralização e federalismo (tendo como referência sua tese de doutoramento, "O processo de descentralização das políticas sociais no Brasil e seus determinantes", concluída em 1998, sob orientação da Profa. Dra. Argelina Cheibub Figueiredo). Também debateu sobre políticas de saúde em artigo de 2002, publicado na Revista Ciência e Saúde Coletiva.

Nesta sua trajetória, destaca-se um trabalho que muito nos inspirou para a realização do evento ao qual se vincula esta 
publicação e também esta entrevista. Trata-se do "Dossiê agenda de pesquisas em políticas públicas", organizado por Marta e publicado na Revista Brasileira de Ciências Sociais em 2003. Neste dossiê, onde procurou-se fazer um levantamento sobre a agenda de pesquisa em políticas públicas à época, apontava Marta Arretche que, embora a institucionalização e a expansão da área fossem positivas e promissoras, elas, em si, não eram suficientes para que os trabalhos produzidos se constituíssem como efetiva contribuição até aquele momento. Na área de políticas públicas, dizia ela, havia muito o que fazer nessa direção. Não obstante o conhecimento acumulado na área, com o passar do tempo os desafios ainda são muitos: dizem respeito tanto à estruturação mais densa do ponto de vista da própria organização e delimitação temática da área de políticas públicas e de seus métodos, quanto às questões que a envolvem, em termos da conjuntura do país e dos respectivos elementos que lhe configuram.

Diante deste contexto, o objetivo da entrevista foi justamente captar a perspectiva da professora Marta a este respeito, praticamente dez anos após a organização do "Dossiê agenda de pesquisas em políticas públicas", para podermos refletir sobre como ela percebe as principais mudanças ocorridas no campo e quais os desafios ainda colocados para a área.

Revista Idéias: Creio que essa entrevista está sendo feita em um momento muito importante da sua carreira, quando você acaba de se tornar professora titular pela USP. Creio que ela pode ser pensada neste clima de comemoração. Eu queria então pedir que você começasse contando um pouco da sua biografia. E contando também como o tema de Políticas Públicas e, em especial, as políticas sociais, começou a compor as suas preocupações acadêmicas.

Marta Arretche: Agradeço suas palavras tão gentis e, obviamente, estou muito contente com o título de professora titular. Quando estudante de graduação na UFRGS [Universidade Federal do Rio Grande do Sul], em Porto Alegre, eu participava 
de movimentos sociais e movimentos de bairro, lá no início dos anos 1980. Porto Alegre é uma cidade que tem uma tradição de associativismo de bairro e à época era um centro com razoável capacidade de mobilização. Mas o que eu frequentemente observava nestas mobilizações é que havia uma grande assimetria de informação entre os movimentos e a burocracia do governo. Nos encontros com representantes da prefeitura, os movimentos eram atendidos por um assessor do assessor do assessor, que comparecia com uma pilha de papéis e apresentava razões técnicas para não atender os pedidos da população. A capacidade de mobilização não correspondia a uma capacidade técnica para entender aqueles argumentos. A única coisa que se entendia era que não dava. $\mathrm{O}$ pessoal dos bairros mais pobres e, portanto, menos escolarizados, tinha dificuldade para entender. Eu era estudante de graduação e tinha uma enorme dificuldade de entender a linguagem técnica da recusa. Então eu lembro de ter decidido claramente: eu vou entender desse negócio.

Quando eu estava para me formar, houve um evento na universidade ao qual compareceu Décio Saes que era professor da Unicamp. Nestes eventos, estudante de graduação é "motorista" do professor convidado. Eu fiquei de "motorista" dele e falei de meus planos, que eram, na verdade, bem vagos. Eu sabia que queria seguir carreira acadêmica e que queria estudar Políticas Públicas. Ele me falou que a Unicamp havia acabado de criar uma linha de mestrado em Políticas Públicas e que também contava com um núcleo de pesquisas. Posteriormente, eu pude entender a honestidade intelectual dele, porque já na Unicamp descobri que ele era radicalmente contrário ao NEPP [Núcleo de Estudos em Políticas Públicas] e àquela linha de pesquisa. Na verdade, à época - meados dos anos 80 - estudar o Estado era entendido como pesquisa "chapa branca". A esquerda acadêmica concebia as políticas do Estado como sendo ditadas exclusivamente pelos requisitos de acumulação do capital. Logo, pensar as políticas de governo era entendido como uma capitulação intelectual. Isto deveria ser combatido e ponto. 
Prestei a seleção e vim fazer mestrado na Unicamp. Foi ótimo, porque aprendi à beça. Tive excelentes professores: Sônia Draibe, Maria Hermínia Tavares de Almeida, Argelina Figueiredo, Vilmar Faria. Fiz excelentes cursos com eles. A escolha por estudar políticas sociais foi em grande parte afetada pelos cursos que eram oferecidos. Argelina Figueiredo oferecia um curso excelente sobre o welfare state, do qual meu trabalho de final de curso virou aquele artigo que publiquei na $\mathrm{BIB}^{2}$ em 199[5]. Como a maior parte dos alunos, minhas escolhas foram induzidas pela oferta. Como postula a teoria do path dependence, a escolha inicial teve muito de aleatoriedade e minha trajetória posterior foi muito dependente desta escolha inicial. Eu poderia ter ido para outros lugares. Poderia inclusive ter ficado no Rio Grande do Sul. Mas a seleção para o mestrado na Unicamp deu certo e eu vim e fiquei porque gostei. Naquela época também não se planejava tanto, as escolhas eram muito mais limitadas.

Revista Idéias: Vamos tratar agora do dossiê de $2003^{3}$ que é fruto de um debate promovido no âmbito do Congresso da ABCP [Associação Brasileira de Ciência Política] de 2002 em que vocês discutiam uma agenda de pesquisas em Políticas Públicas. Este dossiê, na minha perspectiva, representa o início da sistematização mais densa de seu trabalho na área. Mas antes eu queria te perguntar algo, mas acho que você não vai me responder [risos]: como é que você se juntou a essa turma para o debate da $A B C P$ e se você já se percebia como uma possibilidade de referência na área?

Marta Arretche: Esse negócio de que sou uma referência na área para mim é sempre uma surpresa, pois eu vejo os limites do meu trabalho. Na verdade, eu organizei esta mesa porque

2 ARRETCHE, Marta T. S. Emergência e desenvolvimento do welfare state: teorias explicativas. In: Boletim Informativo e Bibliográfico de Ciências Sociais (BIB), n.39, p.3-40, 1995.

3 ARRETCHE, Marta T.S. Dossiê Agenda de Pesquisa em Políticas Públicas. In: Revista Brasileira de Ciências Sociais, v.18, n.51, fev. 2003.

Idéias - Rev. Inst. Filos. Ciênc. Hum. UNICAMP, v.6, n.2, p.311-331, jul/dez. 2015 
coordenava a área de Políticas Públicas na $\mathrm{ABCP}$ nesta época. Eu não tenho absoluta certeza, mas talvez eu tenha sido a primeira coordenadora de Políticas Públicas quando a $\mathrm{ABCP}$ se reestruturou.

Revista Idéias: E como teve início essa área de Políticas Públicas? Você esteve envolvida na sua criação?

Marta Arretche: $\mathrm{Na}$ verdade, a $\mathrm{ABCP}$ havia sofrido uma descontinuidade e foi reorganizada no esteio da formação de associações disciplinares, tais como a SBS [Sociedade Brasileira de Sociologia] e a ABA [Associação Brasileira de Antropologia]. Eu não participei desta fase de reorganização da $\mathrm{ABCP}$.

Revista Idéias: Quando você passou a coordenar, já existia a proposta da área de Políticas Públicas?

Marta Arretche: Sim. Na época, eram apenas seis áreas e a ideia é de que as áreas fossem bem amplas. De fato, meu diagnóstico à época era que os principais desafios da área de Políticas Públicas eram a necessidade de maior densidade teórico-metodológica e a necessidade de descolar a agenda de pesquisa da agenda política. A produção da área era caracterizada por uma imensa quantidade de trabalhos monográficos, que descreviam os fenômenos, mas não dialogavam entre si. Além disto, a ausência de uma ancoragem teórica impedia que o esforço de pesquisa redundasse em algum acúmulo. Eu participava de dezenas de bancas e de eventos. Era como se cada um estivesse começando do zero.

Para que o conhecimento produza acúmulos é necessário que exista um diálogo entre as evidências empíricas e teorias que formulem regularidades do mundo real. Ao tratar de políticas setoriais, devemos produzir generalizações cujo alcance vá além do objeto específico sob análise. O caminho é pesquisar uma área de política ou país para obter interpretações de alcance mais amplo. No início dos anos 2000 estávamos muito aquém disto e isto me parecia ser o nosso principal problema. Isto mudou muitíssimo nos últimos anos. A Ciência Política fez um investimento muito 
grande na formação metodológica de nossos estudantes. Penso que o nosso departamento [Departamento de Ciência Política da Universidade de São Paulo] contribuiu bastante para isso, não apenas para nossos próprios alunos, mas oferecendo a Summer School, aberta para alunos externos. Mas o compromisso com a formação metodológica me parece ser um compromisso da Ciência Política praticada no Brasil, isto é, muitos departamentos têm investido nesta área cujo resultado é uma elevação muito importante da qualidade da produção acadêmica.

Revista Idéias: Atualmente é possível falar de um campo de Políticas Públicas minimamente maduro, em termos desse acúmulo a que você se referia?

Marta Arretche: Minimamente maduro é algo bem difícil de medir. Eu acho que avançou muito, e não apenas na academia. Temos institutos de pesquisas importantes, como o IPEA [Instituto de Pesquisa Econômica Aplicada], a Fundação João Pinheiro... Porque o compromisso de tornar nossas interpretações empiricamente sólidas é um compromisso coletivo. É a área que vai se adensando, assim como o nível do debate. Nós temos boas revistas, boas publicações. A qualidade do debate melhorou muito. A qualidade da informação melhorou muito. Tudo isto foi facilitado por uma mudança radical no acesso a dados. Não precisa sequer sair de casa e nem mesmo ter acesso a informação privilegiada por meio de contatos pessoais para poder fazer boas pesquisas. $\mathrm{O}$ acesso à informação foi muito democratizado. Você pode obter uma quantidade imensa de informação por meio de uma miríade de fontes e produzir bons trabalhos.

Revista Idéias: Em termos teóricos ainda há grandes desafios? Pois há lacunas e questões, por exemplo, ligadas à criação de teorias próprias, vinculadas às dificuldades de adaptação das teorias vindas de fora. 
Marta Arretche: Eu não penso que nossa principal motivação deva ser fundar novas teorias. Eu até acho que essa aspiração de fundar novas teorias, tanto no exterior quanto no Brasil, envolve riscos que não são triviais. Se cada um pretende inventar a roda com seu trabalho, o acúmulo torna-se essencialmente problemático. Parte importante do conhecimento científico é produzido pelo que Thomas Kuhn chama de "ciência normal", em que cada trabalho coloca um pequeno tijolo na elaboração e aperfeiçoamento de um paradigma. Essa pretensão de que seu trabalho vai fundar uma teoria, se praticada coletivamente, é nociva para o desenvolvimento da disciplina. No nosso caso, ela cria uma indisposição para reconhecer o mérito da contribuição que trabalhos anteriores já deram. Isso me parece tão ruim para o acúmulo de conhecimento quanto a importação.

Revista Idéias: Eu me refiro às "ideias fora do lugar", à importação sem muita crítica. Isto também é nocivo?

Marta Arretche: As ideias podem estar fora do lugar quando princípios normativos, formulados originalmente em um contexto, se difundem ou tornam-se universalmente aceitos (como foi o caso do liberalismo econômico, para tomarmos como exemplo a influente formulação de Roberto Schwarz), mas não encontram exata correspondência nas sociedades de destino. Neste caso, estamos falando das tensões envolvidas na implantação no plano doméstico de escolhas institucionais inspiradas por valores e princípios cuja origem é externa.

A dinâmica da produção de conhecimento é inteiramente distinta. Ela não pode ser exclusivamente doméstica, se pretendemos produzir teorias e conhecimento de caráter mais geral. A formulação de teorias é sempre baseada num limitado número de observações empíricas. Sua capacidade explicativa é examinada pela observação posterior de novos casos e de novos contextos. Esta capacidade - que poderíamos chamar de crítica, mas é na verdade, o exame da extensão em que uma dada teoria pode ser aplicada - pode ser refutada ou aperfeiçoada. Para aperfeiçoar 
a teoria, é mais interessante que as ideias estejam fora do lugar, no sentido de que novas dimensões possam ser acrescentadas às proposições originais.

Revista Idéias: Tentando explorar mais aspectos sobre o campo e seus avanços, ainda tendo como referência o dossiê de 2003, você comentava na sua abertura que naquela época não havia muitas dúvidas quanto ao objeto da área e quanto às questões legítimas acerca da investigação. Mas você apontava que havia vários desafios em relação não somente à abordagem teórica, mas também em relação aos métodos de investigação. Avançamos atualmente?

Marta Arretche: Creio que avançamos muito em termos da profissionalização da disciplina, dos parâmetros para avaliar o que é um bom trabalho, do treinamento dos estudantes em termos de metodologia e do domínio das metodologias que são praticadas internacionalmente. Quando eu comecei a trabalhar com Políticas Públicas em mil novecentos e bolinha [risos], conseguir fazer uma tabela de frequência era uma vitória. De um lado, não tínhamos acesso a dados; era muito difícil conseguir dados. Quando elaborávamos o Relatório sobre a Situação Social do País, no NEPP, tínhamos de bater na porta dos Ministérios e conseguir os dados com quem se dispusesse a fornecê-los. De outro lado, nossa capacidade de lidar com os dados era muito limitada. Hoje, nossos alunos e nossos bons profissionais dominam técnicas e parâmetros de produção de referência que são de excelente nível.

Revista Idéias: A disponibilidade de informações, de dados que podem ser trabalhados, também aumentou?

Marta Arretche: O Brasil, até em termos internacionais, é considerado um rich-data country porque você pode ter acesso a uma grande massa de dados, muito desagregados, para todo o Brasil, de base pública e gratuita. Isso é bem difícil de encontrar em muitos países. Mas poderíamos ter dados e a comunidade 
científica não saber como lidar com eles. Mas o treinamento dos alunos hoje é muito avançado.

Por outro lado, hoje corremos o risco de um excesso de quantitativismo, isto é, os pesquisadores lidam com uma massa de dados, mas não têm muito conhecimento substantivo do fenômeno com o qual estão lidando. Neste caso, o significado dos dados com os quais estamos lidando não está ao alcance do pesquisador, porque a interpretação adequada requer saber o que está sendo representado através das evidências empíricas.

Penso que hoje o grande desafio para os departamentos de ciência política é acompanhar a diversificação e a sofisticação teórica e metodológica. A variedade de temas e abordagens está muito além da capacidade de oferta dos departamentos acadêmicos. Nossa comunidade de Ciência Política no Brasil é uma comunidade pequena. Os departamentos têm, de modo geral, de 15 a 20 professores ativos. Qualquer departamento de Ciência Política no Brasil terá muita dificuldade de oferecer disciplinas que acompanhem a sofisticação metodológica e teórica da Ciência Política contemporânea. Uma experiência bem-sucedida em nosso departamento na USP é oferecer cursos de curta duração, em temas específicos, com professores convidados. Neste modelo, é possível ampliar bastante o escopo da formação de nossos alunos.

Revista Idéias: Atualmente há a criação de mestrados profissionais específicos na área de Políticas Públicas. O que você pensa a respeito?

Marta Arretche: Eu sou favorável a ter formatos diversificados de formação sobretudo na área de Políticas Públicas. Nosso sistema de formação é um sistema muito restrito. Está muito orientado à carreira acadêmica, quando, na verdade, mesmo na carreira acadêmica não tem lugar para muita gente. Não há muito espaço na universidade para pessoas que não tenham vocação acadêmica, quando é legítimo adquirir novos conhecimentos sem que você precise produzir uma tese para receber um diploma. Eu sou favorável a diversificar, criar formatos que deem mais alternativa para as distintas vocações das pessoas. Sobretudo, na 
área de Políticas Públicas. Há uma demanda enorme por maior qualificação e a gente só valoriza um formato, que é um formato mais exigente, mais difícil, mais louco [risos]. Cursos de capacitação, cursos de curta duração, cursos de média duração deveriam ser incorporados às atividades regulares da Universidade.

Revista Idéias: Ainda que se tenha avançado na discussão do campo de Políticas Públicas, esta análise, no Brasil, é majoritariamente vinculada ao Estado como principal ator - "o Estado em ação". Como que você avalia a possibilidade de se pensar sob a perspectiva dos vários atores ou de "rede de atores"? A este respeito, lembro de dois comentários que foram feitos ao longo do evento: ${ }^{4}$ a professora Capella ${ }^{5}$ apontou que nos anos de 1990, na terceira geração dos estudos de Políticas Públicas, rompe-se a fronteira entre Estado e sociedade civil, repensando o famoso "triângulo de ferro": o Estado como burocracia, os políticos e os grupos de interesse. O professor Valeriano, ${ }^{6}$ em sua conferência inaugural também neste evento, disse que muitas vezes o Estado é ator e também parceiro da sociedade civil. Ele deu o exemplo da burocracia ambiental, que se vincula à sociedade civil para se fortalecer diante dos outros grupos dentro do próprio Estado. Como é que você avalia essa questão do Estado, enquanto ator fundamental, mas também sua relação com os demais atores, contradições, interações?

${ }^{4}$ II Seminário do Núcleo de Estudos em Políticas Públicas - NEPPs: “Políticas Públicas no Brasil: uma agenda de pesquisa", realizado na Faculdade de Ciências Humanas e Sociais, campus de Franca da Universidade Estadual Paulista - Unesp, de 15 a 17 de outubro de 2013. O evento contou com apoio do Departamento de Relações Internacionais - DERI e da Fundação de Amparo à Pesquisa do Estado de São Paulo - Fapesp.

${ }^{5}$ Profa. Dra. Ana Cláudia Niedhardt Capella (FCLAr, Universidade Estadual Paulista - Unesp), participante da mesa-redonda "Políticas Públicas: fundamentos e atores".

${ }^{6}$ Conferência inaugural ministrada pelo Prof. Dr. Valeriano Mendes Ferreira Costa (IFCH, Universidade Estadual de Campinas). 
Marta Arretche: Esta é uma pergunta bem complexa mesmo. Em primeiro lugar, eu discordo dessa noção do Estado como um ator monolítico, com uma vontade única. Há evidências muito claras na direção apontada pelos teóricos do garbage can model (March e Olsen), de que o Estado funciona como uma anarquia organizada. No interior do Estado, há burocracias com preferências diferentes, atores partidários e governamentais que têm orientações normativas e preferências distintas com relação ao desenho das políticas. Logo, pensar o Estado como um ator com uma preferência única implica ignorar a variedade de interesses e preferências que são abrigadas no interior das instituições estatais.

Diferentemente, eu tendo a aceitar as teorias sobre o Estado que afirmam que as burocracias inseridas no Estado têm vantagens na formulação de políticas porque trabalham em tempo integral e não dependem de recursos privados para atuar. Diferentemente dos atores privados, elas têm capacidade de iniciativa, o que lhes conferem vantagens em relação aos atores e às preferências da sociedade civil. Entretanto, quais interesses prevalecem no desenho final de uma política só pode ser resolvido empiricamente. Há burocracias estatais que articularam coalizões muito influentes, como é o caso da política de saúde no Brasil. Burocracias públicas e movimentos sanitaristas, a partir dos recursos estatais, conseguiram articular uma coalizão que integra interesses privados e públicos muito poderosa, que foi muito bemsucedida na criação de um modelo de saúde bastante próximo de suas preferências.

O contrário também pode ocorrer. Na área de segurança, as burocracias estatais têm preferências muito polarizadas e o resultado é basicamente a paralisia.

Logo, essa vantagem das burocracias públicas é potencial. Só empiricamente você consegue saber se essa potencialidade se realiza ou não.

Mas eu concordo integralmente com a ideia de que interpretar as instituições estatais como isoladas dos interesses articulados privados da sociedade civil implica perder uma boa parte do fenômeno. 
Revista Idéias: Os atores institucionais nem sempre decidem ou fazem escolhas em função de princípios autointeressados, vinculados pura e simplesmente à racionalidade. Alguns trabalhos vêm sendo desenvolvidos neste sentido, mais recentemente, tentando pensar um pouco as concepções dos atores envolvidos nas Políticas Públicas, e suas respectivas instituições, tais como suas visões acerca do que seja o bem ou a justiça, por exemplo. Cito novamente o Valeriano, em sua conferência inaugural e na mesma linha a Carolina Justo, ${ }^{7}$ que salientaram no evento a importância de se pensar como as instituições são sustentadas por atores com princípios diversos e como, ao mesmo tempo, é relevante captar estes diferentes princípios. Portanto, não se trata de uma discussão voltada só à racionalidade, à lógica da escolha racional. Como você avalia essa leitura?

Marta Arretche: Esta é uma pergunta bem complexa. Para responder de modo breve, eu diria que se você não aceitar que os atores políticos têm uma racionalidade, no sentido de que há uma consistência entre suas preferências e suas estratégias, é muito difícil entender a lógica de seu comportamento. Também não podemos aceitar que as preferências dos atores sejam suas preferências declaradas, basicamente porque os atores podem mentir e declarar estrategicamente preferências que são distintas de suas preferências sinceras. $\mathrm{Na}$ ação política, frequentemente observamos que os atores escondem seus interesses privados e formulam suas preferências particulares como preferências de interesse geral.

Todo o problema consiste, portanto, em saber quais preferências orientam a ação dos atores. Eu aceito a formulação do neo-institucionalismo histórico, que estabelece que as preferências não podem ser deduzidas exogenamente, com base nas preferências da classe de atores à qual seu ator de interesse

${ }^{7}$ Profa. Dra. Carolina Raquel Duarte de Mello Justo (Universidade Federal de São Carlos - UFSCar), participante da mesa-redonda "Princípios, implementação e efetividade: as Políticas Públicas em movimento".

Idéias - Rev. Inst. Filos. Ciênc. Hum. UNICAMP, v.6, n.2, p.311-331, jul/dez. 2015 
pertence. Os estudos qualitativos mostram que elementos do contexto e da aprendizagem afetam as preferências dos atores, o que implica uma variedade significativa de objetivos. Penso que comparações intertemporais ou entre países que não controlem as preferências dos atores correm o sério risco de comparar coisas muito diferentes como se elas fossem iguais.

Se assumirmos que os atores não têm clareza das suas preferências, nenhum comportamento político pode ser compreendido, porque seu comportamento fica totalmente aleatório. Para fazer alguma teorização, temos que adotar algumas premissas. Se não assumimos o princípio da parcimônia e simplificamos a realidade para poder estudá-la, o mundo fica infinitamente complexo e impossível de ser compreendido.

O problema é quando os modelos simplificam de tal modo a realidade que começam a distorcê-la e deixam de ser um instrumento útil de interpretação. De qualquer maneira, a ideia dominante de que a racionalidade dos atores é exclusivamente instrumental, não é mais dominante hoje.

Revista Idéias: Esta nova perspectiva traz elementos novos e importantes. Mas por outro lado também traz desafios, do ponto de vista da metodologia. Porque para incorporar essas visões, você entra em um campo de subjetividades. E ainda que se parta dos necessários aspectos mais objetivos para garantir o estudo, como você apontou, mesmo assim é muito difícil.

Marta Arretche: Se você determinar exogenamente que todo político quer se reeleger e que esta premissa é suficiente para entender a lógica de seu comportamento, estará assumindo que políticos não têm interesse substantivo sobre políticas. Se, diferentemente, você assumir que políticos têm interesse em se reeleger, mas também têm interesse substantivo sobre políticas, mais uma vez você poderá determinar exogenamente suas preferências a partir da preferência média do tipo de partido ao qual ele pertence. Entretanto, penso que você estará mais próxima de interpretar seu comportamento se investigar empiricamente 
seus interesses e como eles mudam ao longo do tempo. Portanto, a pergunta que fazemos condiciona a resposta que obtemos. Se sequer nos perguntamos sobre a possibilidade de que preferências não devam ser determinadas exogenamente, nunca saberemos as preferências de nosso ator de interesse.

Revista Idéias: Um dos recursos metodológicos tem sido a análise de discurso. Inclusive, em uma das mesas do evento, o Sidney apresentou seu trabalho nessa linha. O que você acha dessa estratégia?

Marta Arretche: Eu não acredito muito no discurso dos atores, sabe? Atores mentem e os interesses nem sempre são claramente colocados. Os atores geralmente apresentam suas preferências por meio de um discurso aceitável ao público. Eu tendo a aceitar a análise de discurso como uma estratégia complementar à observação do comportamento dos atores no momento em que as decisões são tomadas.

Revista Idéias: Muitas vezes, inclusive pela necessidade de um certo distanciamento de uma dada realidade, analisamos um fenômeno sem ter possibilidades de acompanhar seu processo. E aí você faz o estudo a posteriori. Nestes casos, a análise do discurso acaba sendo um complemento importante, quando o estudo fica restrito, por exemplo, às fontes como documentos e atas.

Marta Arretche: Também não acredito em atas [risos].

Revista Idéias: Em Relações Internacionais a gente usa muito isso...

Marta Arretche: Acho que talvez atas de protocolos internacionais sejam fontes melhores do que, por exemplo, a ata da reunião de uma associação. Eu fiz pesquisa de campo sobre

8 Prof. Dr. Sidney Jard da Cunha (Universidade Federal do ABC - UFABC), participante da mesa-redonda "Políticas Públicas: fundamentos e atores".

Idéias - Rev. Inst. Filos. Ciênc. Hum. UNICAMP, v.6, n.2, p.311-331, jul/dez. 2015 
associações e a primeira coisa que os caras diziam, para provar que a associação existia, era que tinha um livro de atas.

Talvez você tenha razão. Como documento de pesquisa, há atas e atas. Dependendo do objeto de análise, a ata pode ser uma boa fonte de consulta. O que eu acho é que é um investigador não pode acreditar naquilo que os atores dizem sobre si mesmos. Não se pode tomar o que os atores dizem sobre si mesmos pelo seu valor de face. Cabe ao pesquisador interpretar as declarações dos atores e não reproduzir a fala de um ator como uma verdade científica.

Revista Idéias: Pensando um pouco mais agora na relação com a sociedade civil, do ponto de vista da elaboração, da implementação das Políticas Públicas... De certa maneira você já tocou nisso quando falou dos diversos atores, mas eu gostaria que você falasse um pouco mais como é que você vê o papel dela - por exemplo, o papel dos movimentos sociais, das ONGs, etc. Também vinculado a isso, depois gostaria que você falasse um pouco, do ponto de vista metodológico, como você vê a análise das Políticas Públicas na sua relação com as metodologias participativas? Tem se falado muito da importância da questão da participação e muitas metodologias têm tentado incorporá-la. Até que ponto a participação é boa e possível? E, ademais, até que ponto ela é possível sem perdermos de vista a eficiência, a efetividade das políticas?

Marta Arretche: Essa pergunta é um projeto temático da FAPESP [risos]!

Eu acho que o Brasil abriu enormemente, muito mais que outros países, espaços institucionais de participação. Isto é um avanço importante. A extensão em que a sociedade faz uso destes espaços depende de um conjunto de fatores que independende da existência desses canais de participação. Os estudos têm mostrado que os efeitos da participação dependem da existência de movimentos sociais organizados, do nível de escolaridade dos participantes, da abertura das burocracias e do Executivo para essa participação. Portanto, a existência de canais institucionais de participação abre possibilidades de interferência nas políticas. $\mathrm{O}$ 
fato de haver essa possibilidade já é um avanço enorme em relação a outros países e em relação ao passado.

A extensão em que essa possibilidade se converte em resultados efetivos depende de um conjunto de fatores que são contingenciais. Então, é muito difícil ter uma resposta genérica. No livro que organizei sobre as mudanças que ocorreram no Brasil nos últimos 50 anos, que será lançado pela UNESP agora em 2015, ${ }^{9}$ Adrian Lavalle e Leonardo Barone têm um capítulo em que mostra que as associações civis e os conselhos municipais cresceram muito. ${ }^{10}$ Mas cresceram particularmente os conselhos cuja existência é compulsória, nas áreas de políticas em que as regras federais condicionam as transferências à existência dos conselhos nos municípios.

Muitos estudos mostram que há milhares de conselhos no Brasil, milhares de oportunidades de participação, de representação extraparlamentar que de fato não existem em outros países. Isso é um fato. A extensão em que isso se converte em oportunidades de afetar Políticas Públicas, de tornar políticas muito mais eficientes ou eficazes depende de muitos outros fatores. Podemos assumir que a existência dessas oportunidades institucionais é um avanço importante. Em que medida essa possibilidade se converte em resultados efetivos depende de um conjunto de fatores locais, que a gente ainda não sabe muito bem quais são. Mas, de qualquer modo, o que a gente sabe é que os executivos municipais têm uma margem de iniciativa muito grande.

Revista Idéias: $E$ do ponto de vista da metodologia; da inserção de métodos participativos nas Políticas Públicas, desde sua elaboração, implementação e também avaliação? Até que ponto a participação é boa e possível, sem perder-se de vista a eficiência e a efetividade das políticas?

${ }_{9}$ ARRETCHE, Marta T.S. (org.). Trajetórias das desigualdades: como o Brasil mudou nos últimos 50 anos. São Paulo: Editora Unesp, 2015.

${ }^{10}$ LAVALLE, A.G.; BARONE, L.S. Conselhos, associações e desigualdade. In: ARRETCHE, Marta T.S. (org.). Trajetórias das desigualdades: como o Brasil mudou nos últimos 50 anos. São Paulo: Editora Unesp, 2015.

Idéias - Rev. Inst. Filos. Ciênc. Hum. UNICAMP, v.6, n.2, p.311-331, jul/dez. 2015 
Porque uma coisa é a gente pensar isso enquanto possibilidade, que é o que você se referia. E, neste aspecto, precisamos, certamente, considerar a capacidade dos agentes de se organizar para que a participação seja incorporada. Outra coisa é a gente incorporar, enquanto estudiosos e também enquanto gestores das Políticas Públicas essa participação em termos metodológicos.

Marta Arretche: Eu acho que essa é a parte mais difícil. Por que? Primeiro, porque existem concepções muito diferentes do que seja eficiência, efetividade, e mesmo do que seja participação. Então, como você observa empiricamente essas coisas? Entre os estudiosos, mesmo no campo teórico, existe uma divergência muito grande sobre o que seja um bom governo. Tomemos o governo Dilma. Há quem ache que este é um péssimo governo e quem defenda que é o melhor governo que o Brasil já teve. Obviamente, essas conclusões diferentes são produzidas por métricas diferentes do que seja um bom governo. Logo, encontrar indicadores incontroversos do que seja um bom governo, e, portanto, o que seja a efetividade das políticas não é uma tarefa simples. Não é uma tarefa incontroversa.

O mesmo ocorre com relação à participação. Há um debate, que acompanho muito superficialmente, sobre representação e participação nos conselhos. Ocorreu uma "onguização" dos conselhos, o que basicamente quer dizer que as ONGs, que têm menos problemas de ação coletiva, ocuparam espaço nos conselhos em detrimento dos movimentos sociais. A quem estas ONGs representam, além de si mesmas? Se elas não têm delegação de ninguém, elas incorporam uma representação de pior qualidade do que a dos parlamentos. Porque os vereadores, os deputados pelo menos são eleitos. Uma orientanda minha, Olívia Perez, fez um trabalho muito sério com conselheiros. Muitos conselheiros acham que não devem consultar seus eleitores, porque os eleitores não têm opinião abalizada sobre os assuntos tratados nas reuniões dos conselhos. 
Medir participação não é uma questão incontroversa. Esses são temas muito controversos de serem estudados, porque eles são muito afetados por preferências normativas.

Revista Idéias: Eu queria falar um pouco de avaliação de Políticas Públicas, mais especificamente. Claro que esse não é um tema novo no campo, mas há uma tendência a se falar cada vez mais fortemente da importância da avaliação. Não só aquela avaliação pós implementação, mas aquela ideia de monitoramento avaliativo como parte de todo o processo do ciclo das Políticas Públicas. É possível falarmos de um refinamento da área a este respeito?

Marta Arretche: Eu acho super, super, super importante isso. É preciso fazer avaliações independentes. Mesmo avaliações financiadas pelos governos têm que garantir a independência na produção de resultados. Neste caso, a avaliação de PPs, em termos metodológicos, não tem nenhuma diferença da boa pesquisa acadêmica. Os fundamentos são os mesmos.

Revista Idéias: Como é que você entende o debate a respeito de desigualdade versus diversidade para o campo das PPs? Ou seja, as Políticas Públicas ao mesmo tempo que têm que ser diversas, não podem ser desiguais. Quando penso nisso sempre lembro da temática das cotas. Como lidar com essa equação? Ou seja, como lidar com princípios coletivistas e individualistas ao mesmo tempo? É possível pensar em princípios individualistas de forma que estes não sejam excludentes?

Marta Arretche: Esse é um problema bem delicado e que também nãoé de simples solução. Porquenós fomos, digamos assim, socializados em uma cultura do universalismo de procedimentos. Então, quer dizer, as políticas seriam justas na medida em que elas fossem iguais para todos. E, portanto, você criaria igualdade de oportunidades, oferecendo as mesmas oportunidades para todos. A mesma métrica para todo mundo.

Mas, na verdade, existem estudos que mostram que determinadas populações sãotão distintas que, se vocêusar a mesma 
métrica para todos, você não estará corrigindo desigualdades, porque os indivíduos, dadas suas características, não têm condições de se apropriar igualmente das mesmas políticas. Os índios não poderiam ser tratados com o mesmo modelo adotado para os brancos. Você teria que ter escola específica para os índios. Você teria que ter sistema de saúde específico para os índios, assim como para mulheres, para negros, etc. Genericamente, como princípio, eu seria favorável a isso, ainda que seja muito discutido que desenhos de políticas são mais recomendáveis. Há estudos no CEM [Centro de Estudos da Metrópole] que mostram, por exemplo, que o programa de cotas na universidade favoreceu os não-brancos ricos em detrimento dos brancos ricos. Neste caso, você se pergunta que tipo de desigualdade está sendo corrigida.

Então, se você faz um programa de cotas para sistemas altamente seletivos, como é por exemplo a entrada na universidade, você pode não ter como chegar aos pobres na verdade, porque a competição é muito alta. Só entram mesmo os que vêm das melhores escolas. Um programa de cotas para os não-brancos pode trocar a cor dos que entram, mas não necessariamente a classe dos que têm acesso à universidade. Qual seria a justificativa moral para beneficiar os negros ricos em vez dos brancos ricos?

Para reduzir desigualdades, é importante determinar quais fatores produzem desigualdades. É aí que as avaliações fazem muito sentido. Por exemplo, os programas de cotas para aumentar a participação das mulheres na política. Na verdade, a maior parte destes programas é muito pouco efetiva porque há muitos eleitores que não votam nas mulheres. Se a maioria dos eleitores é machista, o único jeito de aumentar o número de mulheres no Parlamento é distorcer a preferência do eleitor. Neste caso, para atender uma preferência normativa você pode ferir outra, que é o princípio da representação. Até que ponto você deve distorcer a preferência do eleitor para atender o princípio de reduzir as desigualdades da participação na política? Estas não são questões simples. Falar genericamente de princípios é bem mais fácil do que examinar casos concretos. 
|331 |

Regina Laisner

Revista Idéias: Marta agradeço muitíssimo a sua entrevista, em nome de todo o NEPPs e de todos os leitores que terão oportunidade de conhecer um pouco mais de suas ideias e aprender com elas. Nosso muito obrigada!

Idéias - Rev. Inst. Filos. Ciênc. Hum. UNICAMP, v.6, n.2, p.311-331, jul/dez. 2015 